\title{
O que há de novo no front dos conservadores?
}

\author{
Eduardo dos Santos Chaves ${ }^{1}$ \\ Vitória Tiscoski Ramos ${ }^{2}$
}

BIROLI, Flávia; VAGGIONE, Juan Marco; MACHADO, Maria das Dores Campos. Gênero, neoconservadorismo e democracia: disputas e retrocessos na América Latina. São Paulo: Boitempo, 2020. 222p.

Resenha recebida em: 24/08/2021

Resenha aprovada para publicação em: 10/10/2021

Na América Latina, a década de 2010 foi marcada pela queda do que se convencionou chamar de "onda vermelha". Fosse por meio de golpes ou eleições, essas mudanças levaram à instabilidade política e ao acentuado crescimento do conservadorismo religioso e do neoliberalismo no continente latino-americano. $\mathrm{O}$ resultado mais visível da chegada desse segmento das direitas ao poder vem sendo demonstrado pelo desprezo às políticas de direitos humanos e aos acordos internacionais de garantia de direitos sexuais e reprodutivos. Dessa forma, para sua autoafirmação diante de outras frações do conservadorismo, tais movimentos transformam seus adversários políticos em inimigos, agindo de modo violento contra movimentos feministas e LGBTQI.

É partindo desses pontos que a obra "Gênero, neoconservadorismo $e$ democracia: disputas e retrocessos na América Latina”, de Flávia Biroli, Maria das Dores Campos Machado e Juan Marco Vaggione, traz as seguintes questões: qual (is) é

\footnotetext{
${ }^{1}$ Doutorando pelo Programa de Pós-Graduação em História da Universidade Federal de Santa Catarina (PPGH-UFSC) - e-mail: educhaves4@hotmail.com

${ }^{2}$ Mestranda pelo Programa de Pós-Graduação em História da Universidade Federal de Santa Catarina (PPGH-UFSC) - e-mail: vitoria.tiscoskir@gmail.com
} 
(são) a(s) novidade(s) desses atuais ataques à agenda da igualdade de gênero e da diversidade sexual? Como esses atores conservadores, sobretudo religiosos, incidem sobre as democracias da região? Quais as consequências do uso do gênero dentro das disputas políticas? E quais são os efeitos da polarização em um contexto de erosão das democracias?

Para responder a tais questionamentos, as autoras e o autor situam historicamente essas disputas no campo moral do conservadorismo religioso na América Latina em um momento de queda do catolicismo e avanço do pentecostalismo a partir da década de 1990. Apesar das discordâncias entre os dois campos religiosos, nos últimos anos foram tecidas alianças entre católicos e pentecostais, como estratégias para agir contra os avanços dos direitos reprodutivos e sexuais, levando essa politização reativa por meio do direito e da política institucional a partir da chamada "defesa da família".

O neoconservadorismo é, portanto, compreendido como uma categoria que define grupos religiosos contrários aos debates sobre gênero, ou seja, como um movimento político e religioso que se organiza de maneira reativa às mudanças na estrutura social e histórica, unindo o conservadorismo cristão ao individualismo da ideologia liberal. Para analisar esse fenômeno, são usadas na obra cinco dimensões que, diluídas nos três capítulos, permitem identificar algumas das matrizes do conservadorismo religioso. A primeira delas é a busca por alianças de diferentes setores, evangélicos, católicos e não-religiosos, permitindo novas formas de atuação política. Já a segunda dimensão refere-se ao crescimento da juridicização da moralidade, enquanto que a terceira, a do neoconservadorismo, é a sua operação em contextos democráticos. Finalmente, a quarta dimensão diz respeito ao seu caráter transnacional e a quinta consiste na relação entre neoconservadorismo e neoliberalismo.

As estratégias se direcionam à reconfiguração fundamental, nesse caso, do Estado laico e sua relação com as autoridades estatal, paternal e de direitos individuais. 
O livro aponta para o desenvolvimento de uma nova temporalidade devido à politização reativa em relação às noções de gênero, reprodução e sexualidade. A categoria "gênero" começou a ser utilizada em discussões acadêmicas ainda na década de 1980 e, como reação, a chamada "ideologia de gênero" teve origem nos anos 1990. Porém, ambas foram transformadas em estratégia política e engajamento coletivo ao longo do tempo. Essa nova temporalidade, segundo as autoras e o autor, transformou as questões de reprodução e sexualidade em pautas politizadas, gerando reações de resistência por parte dos movimentos feministas e LGBTQI e mudando a abordagem dessas questões na agenda de direitos humanos. Por outro lado, a moralidade cristã não admite a autonomia reprodutiva ou o prazer, assim como a "família ideal" defendida pelos grupos religiosos compreendem somente uma relação heterossexual de casamento heteronormativa, na qual filhos e mulheres são administrados pela organização patriarcal. Dessa forma, sob o argumento do combate à chamada "ideologia de gênero", grupos religiosos conservadores se uniram para bloquear avanços de direitos sexuais por meio de políticas públicas e da censura.

Importante mencionar que apesar de não citadas no livro, existem algumas vertentes das religiões cristãs que divergem de perspectivas de combate às discussões de gênero, atuando coletivamente em busca por direitos, como as "Católicas pelo direito de decidir", organização não-governamental internacional atuante principalmente contra qualquer legislação contrária aos direitos reprodutivos e autonomia de mulheres; e as "Evangélicas pela igualdade de gênero", outro movimento que busca a igualdade de gênero, e principalmente o fim da violência contra as mulheres.

Além disso, outro ponto importante e não tocado no livro diz respeito às particularidades do neoconservadorismo em relação ao seu debate com as religiões de matriz africana. Desde a década de 1980, grupos protestantes e sua vertente neopentecostal, por meio da "teologia da prosperidade" e de suas práticas proselitistas, visam à destruição de espaços religiosos de matriz africana. Contudo, atualmente, tais 
práticas ocorrem de maneira simbólica e material a partir de um conjunto de difamações muito bem organizadas midiaticamente por igrejas evangélicas por meio de programas de televisão, jornais impressos, panfletos e postagens em sites na internet. São atribuídos a essas religiões "sequestro de crianças; manutenção de pessoas em cárcere privado; sacrifício de seres humanos; propagação de doenças graves etc." (GUALBERTO, 2011 apud GÓIS; TEIXEIRA, 2020). As violências materiais acontecem a partir de invasões aos terreiros, interrupções de seus rituais, destruições de seus objetos sagrados e humilhações de suas lideranças.

A obra foi dividida em três capítulos, além da introdução e conclusão, nos quais coube a cada uma das três autoras a escrita de um capítulo sobre temas ligados às suas áreas de atuação. No primeiro capítulo, “A restauração legal: o neoconservadorismo e o direito na América Latina”, Juan Marco Vaggione, a partir de seus estudos sobre o direito (VAGGIONE, 2018), desenvolve a questão da juridificação das pautas políticas, na qual as discussões acerca da homossexualidade, da transexualidade e do aborto deixaram de ser criminalizadas para serem amparadas pelo direito. Vaggione defende que, em contrapartida, setores conservadores se intensificaram a partir de ideais tradicionais de família e liberdade de crença, suas pautas e lutas. O neoconservadorismo incluiu questões econômicas neoliberais e uma moralidade sexual específica como estratégia para fortalecimento dentro das direitas. Esse capítulo demonstra como se desenvolveu o processo da consolidação dessa moral cristã por meio do direito, com destaque para a juridificação reativa, unindo o direito à religião, com o Estado regulando o religioso, e os atores religiosos usando o direito como arena e como estratégia para defender e propagar sua moralidade.

No segundo capítulo, "O neoconservadorismo cristão no Brasil e na Colômbia”, a socióloga Maria das Dores Campos Machado argumenta que o neoconservadorismo na América Latina foi resultado de alianças entre evangélicos e católicos em um momento de declínio no número de católicos e de avanço dos pentecostais, sobretudo na 
última década, para promover campanhas anti-gênero e intervenções na esfera pública. A partir dos casos do Brasil e da Colômbia, Machado analisa os usos estratégicos de grupos cristãos e suas políticas em relação à chamada "ideologia de gênero" como mobilização de "pânicos morais" sobre a educação sexual dessas crianças. Pesquisas recentes mostram que a maioria das filiações em religiões evangélicas é de mulheres, que agora têm o papel de transmitir os valores religiosos não somente no espaço familiar, mas também no espaço público, por meio de ativismo em movimentos neoconservadores em disputas com a agenda de movimentos feministas e LGBTQI.

No terceiro e último capítulo, "Gênero, "valores familiares" e democracia”, a cientista política Flávia Biroli, referência em trabalhos sobre gênero e democracia (BIROLI, 2014; 2018), analisa os avanços da atuação dos movimentos feministas, LGBTQI e de direitos humanos entre as décadas de 1980 e 2000 na América Latina, entendendo estes como partícipes em processos de liberalização e democratização a partir da visão de gênero. Por conta disso, foi desenvolvida uma relação conflituosa entre grupos progressistas e conservadores em ambientes mais democráticos, diferentemente dos períodos ditatoriais. Como visto nos capítulos anteriores, Biroli ressalta que o Estado foi um mediador importante nesses conflitos. Entretanto, ela demonstra que as reações contrárias ao gênero fazem parte do que ela denomina de erosão das democracias - ou de desdemocratização - porque abalam justamente as configurações institucionais que deveriam garantir a diversidade, a laicidade, a proteção de direitos de minorias e a liberdade de expressão. Além de servir para legitimar lideranças autoritárias, salvacionistas, outsiders, como podemos assistir recentemente, esses processos abrem caminho para o desequilíbrio da democracia e da cidadania, pondo em risco a agenda da igualdade de gênero e os fundamentos da democracia e do Estado de direito.

Sem desconsiderar que as disputas no campo da igualdade de gênero e da diversidade sexual têm dimensão global, o livro procurou observar mais atentamente os 
aspectos regionais da América Latina, que recentemente passam por um período de atualização do conservadorismo religioso. A obra aponta a sofisticação de uma lógica já antiga como importante avanço analítico, que se utiliza de partidos políticos e vias democráticas do direito para deliberar acerca do gênero e da família. O elo entre o "familismo" e o capitalismo liberal permite que posições neoconservadoras justifiquem desigualdades econômicas e precarizações. O paradoxo está na reação contrária ao avanço de direitos conquistados por lutas de movimentos feministas e LGBTQI, utilizando estratégias que a democracia em crise permite. A hipótese é de que os "atores neoconservadores são também partícipes nos processos recentes de transformação das democracias, em um momento em que, mais uma vez, seu sentido está em xeque" (BIROLI; VAGGIONE; MACHADO, 2020, p. 33). Nesse sentido, pode-se dizer que o livro se situa ao lado de estudos que consideram que tais forças conservadoras não se confrontam com instituições democráticas, mas as instrumentalizam, corroendo-as por dentro, transformando-as, ou, conforme demonstrou Daniel Aarão Reis (2020), desfigurando-as.

Como se verifica, os três capítulos dialogam entre si ao responderem a principal questão da obra: o que há de novo no front dos conservadores religiosos? No entanto, outras perguntas emergem de um livro extremamente instigante para pensarmos os sujeitos e os grupos neoconservadores. A primeira diz respeito ao papel das mulheres no universo neoconservador e, mais especificamente, o caso de líderes evangélicas e suas relações com demais mulheres religiosas. Como compreender as adesões de mulheres de estratos populares a esses movimentos conservadores, levando em conta outros elementos para além da manipulação/instrumentalização de setores hegemônicos sobre os grupos subalternizados? Talvez possamos pensar tal fenômeno a partir das culturas políticas conservadoras, marcadas por outras temporalidades, de longa e média durações, oferecendo assim outras respostas à complexidade do neoconservadorismo. A longa duração, por exemplo, pode nos apontar para as nossas tradições autoritárias - o 
racismo, as desigualdades sociais, o mandonismo, o raquitismo democrático e a discriminação de gênero -, marcadas pelo colonialismo e sedimentadas ao logo dos anos.

Conforme Lilia M. Schwarcz (2019), com a ressalva de que não devem se constituir em variáveis explicativas deterministas para tudo, as tradições também não podem ser subestimadas, uma vez que estruturam sociedades marcadas pelas desigualdades, hierarquias, violências, intolerâncias e discriminações. Pode-se afirmar o mesmo em relação à média duração. Referimo-nos mais precisamente aos períodos posteriores às ditaduras latino-americanas e aos processos de redemocratização a partir do final da década de 1970. Para tanto, deve-se levar em conta a maneira pela qual os “entulhos autoritários” estiveram presentes não apenas nos processos de transição, como nas próprias democracias. Ou seja, de que forma as negociações e as acomodações tomaram espaço no lugar de possíveis rupturas? A partir desses aspectos, quem sabe, pode-se compreender em que medida o fenômeno do neoconservadorismo consegue obter êxito entre parcelas significativas da população, afinal, como bem lembra Marcos Napolitano (2015, p. 14), salvo o caso argentino “[...] não houve rupturas completas entre os Estados dos regimes militares e os Estados democráticos pós-ditaduras, posto que não houve uma significativa desmontagem institucional do autoritarismo, nem a renovação completa de suas elites políticas".

A segunda questão é como o neoconservadorismo se alimenta e se reconfigura a partir de embates e composições entre evangélicos, católicos e seculares? Quem são esses grupos e indivíduos situados dentro dessa espécie de "guarda-chuva" denominado de neoconservadorismo? Sobre este aspecto, é imprescindível uma discussão sobre as direitas no contexto mais contemporâneo. Entendemos as direitas como segmentos que se identificam como forças contrárias a políticas igualitárias, sejam elas voltadas à igualdade civil, social, racial ou entre os gêneros (BOISARD; MOTTA; BOHOSLAVSKY, 2019). Radicalizadas, extremadas, liberais e tradicionais, 
provavelmente são elas, as direitas, que ao firmarem pactos e estratégias de combate aos “inimigos", compõem o que as autoras chamam de neoconservadorismo.

Importante destacar, como fez o filósofo Norberto Bobbio (2011), que a própria luta contra as esquerdas ajuda a estabelecer os contornos das direitas, isto é, suas práticas e suas ações acabam por caracterizar suas facetas, sempre de forma heterogênea. Nesse sentido, o livro, longe de selar definições acabadas ou canônicas sobre o tema, abre possibilidade para que novas pesquisas e estudos sejam realizados sobre esses segmentos conservadores, as direitas contemporâneas, que, como camaleões, se redefinem com o passar do tempo.

\section{Referências bibliográficas}

AARÃO REIS, Daniel. A extrema-direita brasileira: uma concepção política autoritária em formação. Anuario Escuela de Historia, v. 32, p. 01-24, 2020.

BIROLI, Flávia. Feminismo e democracia. São Paulo: Boitempo, 2014.

Boitempo, 2018.

Gênero e desigualdades: limites da democracia no Brasil. São Paulo:

BOBBIO, Norberto. Direita e Esquerda: razões e significados de uma distinção política. São Paulo: UNESP, 2011.

BROWN, Wendy. Nas ruínas do neoliberalismo: a ascensão da política democrática no ocidente. São Paulo: Politéia, 2019.

GÓIS, João; TEIXEIRA, Kamila. Neoconservadorismo e a ofensiva contra as religiões de matriz africana no Brasil. Fronteiras \& Debates: Macapá, v. 7, n. 2, jul./dez. 2020, p. 99-112.

- Violência Religiosa e Formas de Resistência: o caso dos cultos de matrizes africanas. Oikos: Viçosa, v. 32, n. 2. 2021, p. 01-26.

MOTTA, Rodrigo Patto Sá; BOHOSLAVSKY, Ernesto; BOISARD, Stéphane (Orgs.). Pensar as direitas na América Latina. São Paulo: Alameda, 2019.

NAPOLITANO, Marcos. Recordar é vencer: as dinâmicas e vicissitudes da construção da memória sobre o regime militar brasileiro. Antíteses (Londrina), v. 8, p. 9-44, 2015. 
SCHWARCZ, Lilia Moritz. Sobre o autoritarismo brasileiro. São Paulo: Companhia das Letras, 2009.

VAGGIONE, Juan Marco; BERGALLO, Paola; JARAMILLO SIERRA, Isabel. El aborto en América Latina: estrategias jurídicas para luchar por su legalización y enfrentar las resistencias conservadoras. Ciudad de México: Siglo XXI Editores, 2018

VAGGIONE, Juan Marco; MORÁN FAÚNDES, José Manuel. Laicidad and Religious Diversity in Latin America. Springer, 2017. 